Escritura y Pensamiento

20-24(40-48), 2021, 317-340

\title{
EL CONTRAPUNTO EN LA CUMANANA Y EN EL CARNAVAL ANDAHUAYLINO (PUKLLAY TAKI)
}

\author{
THE COUNTERPOINT IN THE CUMANANA AND THE \\ ANDAHUAYLINO CARNAVAL (PUKLLAY TAKI)
}

\section{O CONTRAPONTO NA CUMANANA E NO CARNAVAL ANDAHUAYLINO (PUKLLAY TAKI)}

\begin{abstract}
Dionicia León Soncco ${ }^{1}$
Universidad Nacional Mayor de San Marcos Esandino - Estudios Andinos de Interculturalidad: quechua y aymara dionicia.leon@unmsm.edu.pe ORCID: 0000-0002-8904-6368
\end{abstract}

Recibido: 9/03/21

Aceptado: 20/03/21

1 Estudió Literatura y Lingüística en la Universidad Nacional de San Agustín de Arequipa, actualmente estudia un doctorado en Literatura Peruana y Latinoamericana en la Universidad Nacional Mayor de San Marcos. Realizó labor docente en la Universidad Nacional Micaela Bastidas y en la Universidad Nacional José María Arguedas. Se desempeña como especialista en Proyección Social en la UNAJMA; es miembro voluntario del Comité Ambiental Universitario (impulsa el uso responsable de las bolsas plásticas, el amor y cuidado por la naturaleza) y de la Cátedra Arguedas en la misma universidad, así como del grupo Poético Brétema de Vigo en España. 


\section{Resumen}

En el Perú, por su diversidad cultural y geográfica se puede encontrar una riqueza de manifestaciones a lo largo de su territorio, así encontramos expresiones artísticas vinculadas a cada pueblo, a cada cultura. Algunas similares y otras singulares que se han mantenido en la memoria colectiva de su gente, ya que se trasmiten generación en generación y se mantienen vivas, gracias a las familias que cultivan el arte o a las instituciones que lo propician.

En el caso de la literatura de tradición oral andina y afroperuana que también constituyen parte del patrimonio cultural de nuestro país, encontramos algunas particularidades entre las diversas formas expresivas orales y musicales.

Se realizará una comparación entre el contrapunto en la cumanana y en las coplas del carnaval andahuaylino (pukllay taki), porque se advierte en ellas ciertas características similares en su composición y en su interpretación.

Palabras clave: contrapunto, cumanana, coplas, carnaval andahuaylino, pukllay taki.

\section{Abstract}

In Peru, due to its cultural and geographical diversity, a wealth of manifestations can be found throughout its territory, thus we find artistic expressions linked to each people, each culture. Some similar and other unique that have remained in the collective memory of its people, since they are transmitted from generation to generation and are kept alive, thanks to the families that cultivate art or the institutions that promote it.

In the case of Andean and Afro-Peruvian oral tradition literature, which also constitute part of the cultural heritage of our country, we find some peculiarities among the various oral and musical expressive forms.

A comparison will be made between the counterpoint in the cumanana and in the Andalusian carnival verses (pukllay taki), because certain similar characteristics can be seen in their composition and interpretation.

Keywords: counterpoint, cumanana, coplas, andahuaylino carnival; pukllay taki.

\section{Resumo}

No Peru, devido à sua diversidade cultural e geográfica, uma riqueza de manifestações pode ser encontrada em todo o seu território, por isso 
encontramos expressões artísticas ligadas a cada povo, a cada cultura. Alguns semelhantes e outros únicos que permaneceram na memória coletiva de seu povo, pois são transmitidos de geração em geração e se mantêm vivos, graças às famílias que cultivam a arte ou às instituições que a promovem.

No caso da literatura de tradição oral andina e afro-peruana, que também fazem parte do patrimônio cultural de nosso país, encontramos algumas peculiaridades entre as diversas formas de expressão oral e musical.

Será feita uma comparação entre o contraponto na cumanana e nos dísticos do carnaval andaluz (pukllay taki), pois certas características semelhantes podem ser vistas em sua composição e interpretação.

Palavras-chave: contraponto, cumanana, coplas, carnaval da andahuaylino, pukllay taki.

Nosotros hacemos las cumananas, no las recopilamos ni las sacamos de los libros. En las fiestas o en los chicherios, nacen de la creatividad. Cuando nos cogen frios, no siempre tenemos el valor. Por eso, los sentimientos más profundos los expresamos con calentura con un trago adentro.

Maritza de Jesús García Reyes

En el carnaval andahuaylino urbano, las mujeres citadinas visten con llamativas polleras y con ponchos, los varones. Forman pandillas, van por las calles y plazas $y$ se producen alegres confrontaciones con otras comparsas. Se incluyen la guitarra, el violín, el acordeón, la mandolina y la tinya del campo los que animan el contrapunto de canciones picarescas, para finalmente todos juntos compartir comidas tipicas y bailar incansables alrededor de las yunzas.

Luis Rivas Loayza 


\section{Introducción}

La rica diversidad cultural en el Perú está conformada por los pueblos nativos amazónicos, quechuas, aymaras y por los pueblos que migraron a nuestro país por múltiples circunstancias; entre ellos, del continente africano y de los pueblos orientales. Todos ellos ahora conforman nuestro universo cultural. En este estudio nos ocuparemos de algunos aspectos de las formas expresivas y musicales de la cultura afroperuana y la cultura quechua.

En la cultura afroperuana advertimos diversas manifestaciones culturales, mencionamos algunas: las danzas (son de los diablos, tondero, etc.), los géneros musicales (festejo, landó, etc.), las canciones (amor fino, villancico, etc.) y los géneros literarios (cumanana, copla y décima). Todas estas expresiones tienen un carácter festivo, alegre, rítmico acorde a sus creencias en donde se conjugan otros elementos como la vestimenta, gastronomía, religión; a pesar de tener un antecedente de opresión y marginación. Igualmente, en la cultura quechua se desarrollan múltiples manifestaciones: danzas (toril, danza de las tijeras, trilla, entre otros) los géneros líricos musicales (huaino, harawi, mulisa, cashua, pukllay taki, etc.) vinculados a la cosmovisión andina, pues se interpretan en diferentes momentos del año en relación con los rituales asociados a las creencias y constituyen la fuerza vital de los hombres del ande. De estas dos culturas analizaremos la cumanana y el carnaval andahuaylino.

\section{Sobre la cumanana y el carnaval andahuaylino}

No se conoce el significado etimológico de la cumanana, sin embargo, su práctica sigue vigente en la zona norte del Perú, especialmente en el departamento de Piura. Generalmente se ejecuta en las reuniones sociales privadas entre familias, o en espacios más abiertos o públicos como las chicherias. También se propician en ámbitos educativos a través de festivales que 
se organizan en instituciones educativas como una manera de promover su difusión, pero sobre todo para que este género discursivo se mantenga en la memoria de los pueblos, y siga el encadenamiento generacional, puesto que, este relevo que se produce mediante las generaciones posibilita que se extienda en el tiempo. Alarcón, afirma:

La cumanana piurana que, como ya hemos dicho, es la misma copla que se conoce en otros lugares del norte del Perú, es también música y letra, en las que es posible rastrear el espiritu de las viejas etnias que antes del arribo de los españoles habitaron en esta parte del país. Su música, de neta raigambre indigena, es monótona y lastimera, y su letra -donde el castellano se ha impuesto como instrumento expresivo- aborda mayormente temas propios del hombre andino, a través de cuartetos, con versos por lo general octosílabos, cuya rima puede ser asonante, consonante o combinada, aunque casi siempre prevalece la segunda. (1992, p. 11)

Esta cita es bastante ilustrativa; por ejemplo nos cita el espacio donde la cumanana se enraíza y cultiva (el norte); además muestra el horizonte temporal y lo fija como anterior a la llegada de los españoles. Es decir, su forma e interpretación ritual es nativa. En cuanto a las características propias del género, encontramos la monotonía, debido a la repetición en la composición e interpretación, el mensaje es doliente, y los temas son situados a su contexto; además las propiedades formales también son definidas; por ejemplo, la composición y articulación de los versos: así son dominantes los octosílabos en cuanto a la métrica, y en el ritmo, prevalece la combinación entre asonante y consonante. La composición de las estrofas generalmente son cuartetos.

Una definición más descriptiva la encontramos en el diccionario etimológico de Julio Calvo, quien explica que cumanana es palabra africana que significa "esperar respuesta 'kúmana hacer probar; rivalizar; hacer cesar. Kuma disputar, copla 
popular". Quien las interpreta es el cumanero: oficio de componer cumanas, además informa Calvo que Chanela Vázquez explica que "Kuamnana es un vocablo de origen africano que en lengua kikongo significa especial relación recíproca entre personas que poseen saber, que tienen el conocimiento" así habiendo hecho, desajustadamente, el cambio man- 'cesar' del kikongo por 'saber' del mandinga para dar mayor relieve al contenido" (Calvo, 2014, p. 273). Entonces, esta es una manifestación afro que se cultiva en la costa norte del Perú.

En las comunidades andinas se presentan diversas manifestaciones musicales según sean los ciclos de vida, ya sea para la siembra, para cosecha, esto dentro del ciclo agrícola; pero también existen géneros musicales que se interpretan más en tiempos urbanos, siempre siguiendo un ciclo temporal, por ejemplo, llega el carnaval, el pukllay, que es un tiempo de alegría y agradecimiento a las divinidades andinas; entonces se enmarca dentro un desarrollo ritual. El carnaval andino para su interpretación articula canto y danza. Para ello se componen los llamados pukllay taki, los cantos carnaval.

Esta nominación se produce como resultado de la fusión de dos palabras quechuas. Pukllay que significa "Juego acción de jugar. Diversión, entretenimiento a pasatiempos, Holgarse o expansionarse. Moverse ciertas cosas. Haber cambiantes en la luz. Jugar carnavales, carnavalearse" (Lira y Mejía 2008:330). Y taki que significa "Cántico, canción, canto. Música vocal. Cualquier melodía para cantar. Emisión melodiosa de las aves. Cierto ruido inicial del agua por hervir" (Lira y Mejía 2008:485).

En específico, las coplas del carnaval andahuaylino son composiciones mayormente satíricas que forman parte del proceso festivo del carnaval, conocido también como pukllay y que generalmente se realiza en el mes de febrero como una manifestación ancestral del pueblo que agradece a través de su cantos y bailes la fertilidad de la Pachamama, pidiendo que sea un año mejor de bienestar y fecundidad, así como del florecimiento del 
amor. Así, el pukllay está asociado al tiempo de fertilidad, en dos horizontes tanto en el humano como en el divino. En el humano porque como producto de estos rituales se producen los encuentros amorosos, por el ánimo que se vive; así varios son hijos del pukllay, porque en el tiempo de esas danzas y fiestas se producen las fecundaciones, todas rituales y respetuosas. En lo divino, en estos cantos también se produce la reciprocidad, mediante el canto, la ch'alla (rociar ceremonialmente agua sobre la tierra), porque se integra a la fiesta, a la Pachamama, que es la madre germinadora, esta reciprocidad hace que los años sean más venturos, porque se canta y celebra la fertilidad de la tierra. Por ello, febrero es un mes de la fertilidad de la tierra y de los hombres.

Al respeto Arguedas manifiesta que: "El carnaval es la fiesta más grande de los pueblos indios peruanos. No conocemos bien su origen. Pero tiene sus danzas propias y su música propia. Y es la más hermosa música de todo el folklore peruano (1942, p. 120). En efecto, la música y danza es la que se interpreta en los momentos rituales de los pueblos indios, que tienen una extensión considerable tanto en el tiempo, porque es bastante distante, y el espacio, porque se interpreta en todos los pueblos del ande.

En Andahuaylas podemos distinguir dos tipos de carnaval: el urbano y el rural. Cada uno concibe y festeja a su modo el carnaval, aunque hay elementos que se intercambian como el uso de algunos instrumentos musicales (tinya y el cascabel) y otras que se contraponen, como el contrapunto en las coplas que solo se da en el carnaval urbano o citadino muy influenciado por los elementos culturales de los colonizadores, debido a que en España existen estas interpretaciones en donde se combina la poesía y la música.

La interpretación del carnaval tiene también una función social reguladora. Al respecto, Navarro menciona: "el carnaval es una fecha para la cual se reservan las luchas o peleas individuales y colectivas de reivindicación o venganza porque gozan 
de cierta inmunidad y tolerancia por parte de las autoridades" (1943, p. 2). A esta idea del contrapunto, o competencia se denomina en el quechua como atipanakuy "competir, concursar, medir las facultades, entablar contienda, porfiar con conato: altercar, disputar con denuedo" (Lira y Mejia, 2008, p. 51). Este sentido de competencia en el mundo andino está registrado con bastante antigüedad, así se encuentra en Dioses y hombres de Huarochiri, cuando Huatyakuri enfrenta a su contrincante para imponer su respeto.

Dentro del mundo andino existen varios géneros artísticos que tienen esta práctica como los kutichiy, los toriles o los kaminakuy, la guerra de los insultos. Dentro de este contexto se contextualiza el pukllay taki, como canto festivo, que confronta, compite. Es precisamente en este tiempo cuando se relajan las normas, y se abre la posibilidad de responder, porque está permitido; así en el ritual del canto atrevido, se pude establecer "luchas" y "venganzas", que en otro tiempo seria imposible, por la solemnidad; mientras que, en tiempo de carnaval, las autoridades carecen de autoridad, y se impone la fiesta.

Podemos observar que tanto la práctica de las cumananas como las coplas se dan en diferentes espacios; en cuanto al tiempo la cumanana se interpreta en cualquier tiempo del año, mientras que los carnavales se celebran solo entre los meses de febrero y marzo y están regidos por un calendario agrícola. En estos dos géneros hay un elemento vinculante, su carácter de competencia, de contrapunto, que pueden ser individuales o colectivos. Precisamente, nos fijaremos en resaltar el contrapunto en la cumanana y en el carnaval andahuaylino, para ello presentaremos una definición previa, luego proponemos las letras, para ejemplificar, esto nos permitirá articular la cosmovisión de dos universos culturales, como el afro y el andino, que revelan la rica diversidad cultural de los nuestros, del que José María Arguedas decía "no hay país más diverso, de olores, colores, sabores", diverso también en sus cantos. 


\section{E1 contrapunto}

El contrapunto es el contraste simultáneo entre dos cosas, bandos, actitudes, de propuesta y respuesta espontánea siguiendo determinadas formas o normas que se valoran por su capacidad creativa.

En el diccionario de la Real Academia Española encontramos las siguientes acepciones:

1. m. Mús. Concordancia armoniosa de voces contrapuestas.

2. m. Mús. Arte de combinar, según ciertas reglas, dos o más melodías diferentes.

3. m. Contraste entre dos cosas simultáneas.

4. m. Arg., Bol., Chile y Ec. Desafío de dos o más poetas populares.

5. m. Ven. Ejecución musical en la que compiten dos cantadores.

Incluida la entrada contrapuntarse, que significa picarse o resentirse.

El contrapunto en las cumananas se da en forma de enfrentamiento o competencia, ya sean recitados o cantados de forma espontánea o creativa generalmente de varón a mujer por turnos y la temática. Según Rocca (2010) "En Zaña, las controversias tuvieron la denominación de partidos. Hubo desafíos de diferentes tipos 1. de decimistas 2) de canto (incluía tonderos, tristes o yaravies 3) de cuartetas, cuartillas o coplas" (p. 224). Entre los cumananeros (así se les llama a los que practican este tipo de género de canción competencia) tenemos sobre todo a los que provienen de la zona norte del Perú (Tumbes, Piura y Lambayeque): Fernando Barranzuela, Nicanor Sandoval León, Juana Francisca Araujo Barranzuela, entre otros.

Mientras que el contrapunto en las coplas del carnaval andahuaylino se dan también en competencia espontánea, a esta forma de lucha se denomina también atipanakuy 
(enfrentamiento). En cuanto a su interpretación es colectiva, así se forman grupos o pandillas de integración mixta por varones y mujeres; lo que los une es la identidad de grupo. También se pueden agrupar por géneros: bando de mujeres y bando de varones; entre ellos se produce la interpretación jocosa y pícara, porque circula entre ellos la sensualidad. La forma de reconocer al ganador se da a través la cantidad de coplas, pero sobre todo se reconoce al grupo que canta coplas más creativas; también en la resistencia y capacidad de respuesta, ya que es un juego de ida y vuelta. Cuando un bando canta, el otro debe responder inmediatamente, improvisando creativamente, y gana el que mantiene el ritmo sin quedarse en silencio.

Entre las comparsas culturales de la zona urbana de Andahuaylas que cada año practican los contrapuntos en los carnavales tenemos a los del barrio Kichkapata (lugar de nacimiento de José María Arguedas), del Centro Poblado de Ccoñeccpuquio, Curibamba, San Carlos, Sanjichu papi, Sunqu sua, Quyllur, Warma Kuyay, Hijos de Talavera, etc.

\section{Comparación del contrapunto entre la cumanana y en las coplas del carnaval}

De acuerdo las observaciones realizadas en el campo y a lo revisado en las fuentes bibliográficas, presentamos una clasificación comparativa del contrapunto entre la cumanana y las coplas del carnaval andahuaylino; según el espacio donde se practican, el tratamiento temático, las formas de ejecución, vigencia y composición literaria que nos permita tener una referencia de las similitudes y diferencias en ambas formas expresivas orales y musicales.

\section{a) Según espacio y tiempo donde se practican}

Hacen referencia a los lugares y temporadas donde se practican los contrapuntos en ambos géneros vigentes. 


\begin{tabular}{|l|l|}
\hline \multicolumn{1}{|c|}{ La cumanana } & Las coplas del carnaval \\
\hline - Chicherías & $\begin{array}{l}\text { - Solo en el tiempo del } \\
\text { carnaval, en las calles } \\
\text { - Fiestas sociales }\end{array}$ \\
- Festivales & $\begin{array}{l}\text { y plazas entre febrero y } \\
\text { marzo. } \\
\text { - Instituciones educativas (difusión) } \\
\text { - Se practican en cualquier momen- } \\
\text { to del año, no hay una fecha deter- } \\
\text { minada. }\end{array}$ \\
\hline
\end{tabular}

Notamos una diferencia entre el espacio y el tiempo pues, las cumananas, las podemos oír en cualquier ocasión durante el año, en reuniones familiares, fiestas patronales, concursos regionales, pero en espacios cerrados. En el caso del carnaval, solo durante febrero y marzo; sin embargo el espacio es más abierto, se ocupan las calles y plazas en donde participan todos desde los más pequeños hasta los más adultos; puede ser de día o de noche. Arguedas describe:

En la noche del martes, se oye de repente, el wayno de carnaval, tocado por muchas guitarras y cantado por un gran coro. Por las cuatro esquinas entran a la plaza largas cadenas de hombres y mujeres, zapateando, cantando en voz alta. En la punta de la wifala van tres, cuatro, a veces ocho y diez guitarristas. ¡Cantan la danza del carnaval en kechwa!... Cien, doscientas voces de hombres y mujeres: Chayraqmi, chayraqmi chayaykamuchkani, según sea en Andahuaylas o Talavera (...) En la plaza está cantando toda la gente del pueblo. La plaza es el corazón para el pueblo. (1938, p.15-16)

\section{b) Por su temática}

Son los temas que abordan estas formas líricas de la tradición oral y musical. Esto quiere decir que responden a un contexto situacional. 


\begin{tabular}{|l|l|}
\hline \multicolumn{1}{|c|}{ La cumanana } & Las coplas del carnaval \\
\hline - Amorosos & - Picarescos \\
- Despreciativos & - Amorosos \\
- Picarescos & - Despreciativos \\
- Del patriotismo & \\
- Politicos & \\
- En forma de adivinanzas & \\
- De preguntas y respuestas & \\
\hline
\end{tabular}

Notamos que las cumananas tienen una variada temática a comparación de las coplas del carnaval donde resalta sobre todo lo picaresco. Pero según lo revisado en los vídeos de las redes sociales, las cumananas que más se difunden en las Instituciones Educativas son los de tipo despreciativo, relacionado a la decepción amorosa. Al igual que las de sentido picaresco con contenido sexual; por ejemplo, las cumananas creadas por Fernando Barranzuela, el mayor cumananero de Yapatera en Piura:

Para penar vino el hombre en este mundo traidor no importa que el hombre pene cuando más pene, mejor.

\section{c) Forma de ejecución}

Responde a los aspectos que toman en cuenta al momento de la ejecución en cuanto a número (cantidad), género (femenino, masculino), uso de instrumentos musicales, factores que determinan el cierre o continuación del contrapunto en la cumanana y las coplas del carnaval. 


\begin{tabular}{|c|c|}
\hline La & Las copla \\
\hline $\begin{array}{l}\text { - De varón a mujer y viceversa (se han } \\
\text { registrado contrapuntos entre afrodes- } \\
\text { cendientes y un indígena o un afrodes- } \\
\text { cendiente y mujer blanca). } \\
\text { - De varón a varón. } \\
\text { - Pueden ser cantadas o recitadas con } \\
\text { acompañamiento musical de guitarra y } \\
\text { cajón, antes de arpa y vihuela. } \\
\text { - Forman parte de un repertorio de otros } \\
\text { géneros populares. } \\
\text { - A veces terminan en un baile o en dis- } \\
\text { cusiones y peleas. }\end{array}$ & $\begin{array}{l}\text { - Se cantan en grupo o pandillas, } \\
\text { que pueden estar conformados } \\
\text { por varones y mujeres y también } \\
\text { solo de varones y mujeres. } \\
\text { - Son cantados con acompaña- } \\
\text { miento de quenas, guitarras, } \\
\text { acordeón, violín, mandolina, } \\
\text { charango, etc. } \\
\text { - Terminan cuando uno de los } \\
\text { grupos se queda en silencio sin } \\
\text { poder contestar para luego rei- } \\
\text { niciar con el baile o compartir } \\
\text { una comida. }\end{array}$ \\
\hline
\end{tabular}

Observamos que existen diferencias en cuanto al número de los ejecutantes, mientras que en las cumananas son de una persona contra otra, en las coplas del carnaval son de un grupo de personas frente a otro grupo de personas, esto porque los carnavales son fiestas masivas donde todos se alegran y salen a disfrutar sin importar la edad.

Sin embargo, en cuanto al género en las cumananas, existen más combinaciones como de varón a varón, característica que no se da en las coplas del carnaval.

Notamos también que las cumananas tiene dos formas de ser presentadas: como canción o declamada; a comparación de las coplas del carnaval que solo son cantadas. Sin embargo, en ambos casos, se hacen uso de acompañamiento musical.

Tanto en las cumananas como en las coplas del carnaval, el contrapunto tiene un carácter dinámico. El maestro de las cumananas Nicanor Sandoval León, testimonia que "A veces la contendora busca el desafío del baile, por lo que la cumanana termina con un tondero (entrevista realizada por Jesús Raymundo Taipe 25/08/2008 de la revista Variedades). Las cumananas, cantadas o recitadas generalmente terminan en un baile o en discusiones o peleas. Mientras que el contrapunto en el carnaval solo cantado y solo termina cuando una de partes se 
queda en silencio, sin la capacidad de responder creativamente al grupo contrincante, para continuar con el baile característico del carnaval o en una comida.

\section{Contrapunto que termina en baile}

Varón: Señora mía

yo siempre soy sincero

aunque usted no lo sepa

yo sé bailar bien mi tondero.

Mujer: A ver, vamos pues, que me lo demuestre

aunque pobre soy

yo te apuesto lo que cueste

y nos bailamos el tondero.

(Contrapunto entre Nicanor Sandoval León y Juana Francisca Araujo Barranzuela)

\section{d) Según la vigencia}

Es la manera de cómo actualmente se evidencia su práctica y la forma cómo se difunde y se da a conocer en el medio.

\begin{tabular}{|l|l|}
\hline \multicolumn{1}{|c|}{ La cumanana } & \multicolumn{1}{c|}{ Las coplas del carnaval } \\
\hline - Al ser una práctica de dos & - Cada agrupación mantiene y renueva su \\
personas, no se evidencia su & repertorio de contrapuntos. \\
práctica masiva. & - Constituye una pieza infaltable en los \\
- Actualmente se difunden en & carnavales. \\
los colegios o festivales. & - El carnaval es una de las fiestas más \\
& importantes, pueden prolongarse hasta \\
& un mes. \\
\hline
\end{tabular}

Carazas (2017): “Los géneros de canciones de competencia desarrollados en el norte y en el resto del país van disminuyendo hasta dejarse de practicar muchos de ellos. Ya solo quedan [...] la décima, la copla y la cumanana como prácticas más difundidas" (p. 30). 
El contrapunto en el carnaval constituye parte fundamental en el desarrollo de la fiesta, que permite la compenetración entre los que son parte de ella, en donde se trasmite su alegría mediante el canto, el baile. No necesariamente se requiere de un concurso o un festival para ponerlo en práctica, es algo que se vive profundamente sin que haya un público de por medio porque todos son parte de la celebración. El historiador José Vega (2001) hace referencia al carnaval de Andahuaylas de la región Apurímac por ser "el más festivo de melodía alegre y el más picaresco". Esta provincia constituye un escenario más de testimonio porque mantiene viva su tradición a buen recaudo.

\section{e) En su composición literaria}

Nos permite conocer los aspectos literarios que resaltan en su composición, los recursos estilísticos y estéticos de las piezas poéticas conjugadas con la música.

\begin{tabular}{|c|c|}
\hline \multicolumn{1}{|c|}{ La cumanana } & \multicolumn{1}{c|}{ Las coplas del carnaval } \\
\hline - Son cuartetos con versos por & • Son versos libres, algunas veces \\
lo general octosílabos con rima & octosílabos, con rima consonante o \\
asonante, consonante o combi- & combinada. \\
nada. & - También se utilizan metáforas, hi- \\
- Se utilizan metáforas, hipérbo- & pérboles, personificación, eufemis- \\
les, personificación, eufemis- & mos, sinécdoques, etc. \\
mos, sinécdoques, etc. & - Los primeros versos también presen- \\
- Los dos primeros versos presen- & tan la misma idea propositiva y las \\
tan una idea propositiva y dos & últimas a manera de conclusión o \\
últimas como una conclusión o & resolución (como es cantado se repi- \\
resolución. & ten dos veces cada dos versos). \\
\hline
\end{tabular}

\section{Clasificación de los contrapuntos según la temática}

Veamos ahora algunos contrapuntos de cumananas frente a las coplas del carnaval andino o pukllay taki; algunos recopilados y otros creados por sus autores, donde evidenciaremos algunas similitudes y diferencias en su temática, interpretación y composición literaria. 
Rima: rimas asonantes, consonantes y combinadas

Temática: despreciativos, picarescos y amorosos.

Métrica: No es precisa porque varía, pueden ser estrofas de cuatro versos octosílabos o, heptasílabos o eneasílabos.

Figuras retóricas: metáforas, hipérboles, hipérbaton, símil, eufemismos, anáforas, etc.

\section{a) Contrapuntos despreciativos}

Los contrapuntos despreciativos se caracterizan porque existe una connotación de superioridad de uno frente al otro, haciéndole notar su orgullo por algo que uno tiene y al otro le falta o recurriendo a sus defectos para rebajarlo. Puede pasar también que se resalte al inicio los aspectos positivos de la persona y al final sus defectos de tal manera que el aspecto negativo resalta más que lo positivo. Los contrapuntos despreciativos generalmente se dan por decepción amorosa o cuando son de diferentes lugares para afirmar su posicionamiento como mejor lugar que el otro.

\begin{tabular}{|c|c|}
\hline La cumanana & Las coplas del carnaval \\
\hline $\begin{array}{l}\text { Varón: Que señora tan prejuiciosa } \\
\text { que viste bonito vestido } \\
\text { ojalá que con el tiempo } \\
\text { encuentre bonito marido. } \\
\text { Mujer: Y de eso ni pensarlo } \\
\text { que yo sabré escoger } \\
\text { aunque los hombres de ahora } \\
\text { lo que quieren es merecer. } \\
\text { (Contrapunto entre Nicanor Sandoval } \\
\text { León y Juana Francisca Araujo Ba- } \\
\text { rranzuela) }\end{array}$ & $\begin{array}{l}\text { Varones: La mujer que a mí me quiera } \\
\text { que me atienda todo el día } \\
\text { y si no me atendiera } \\
\text { otro amor yo buscaría } \\
\text { otro amor no faltaría. } \\
\text { Mujeres: El hombre que a mí me quiera } \\
\text { que me atienda todo el día } \\
\text { y si no me atendiera } \\
\text { el huevo le sacaría } \\
\text { y a mi perro le daría. } \\
\text { (Contrapunto popular) }\end{array}$ \\
\hline
\end{tabular}


- En las cumananas: El locutor se dirige a su alocutario utilizando adjetivos calificativos en los dos versos de inicio y en los dos últimos versos concluye sutilmente haciendo referencia a que, si se viste bien, encuentre a alguien que también lo merezca. En respuesta, su alocutario, le hace saber que ella es quien elige, por más que las formas hayan cambiado. Se nota que la rima es más armoniosa.

- En las coplas del carnaval: En los primeros versos se inician con una proposición condicionante, desafiante en caso sea despreciado por la pareja elegida. La misma posición toma su alocutario, pero siendo más agresiva y despreciativa. En estos versos se hacen uso de anáforas, para mantener el ritmo.

\begin{tabular}{|c|c|}
\hline La cumanana & Las coplas del carnaval \\
\hline $\begin{array}{l}\text { Mujer: Anda cholo palangana } \\
\text { con harta chicha en la panza, } \\
\text { cómo quieres que te quiera si la } \\
\text { plata no te alcanza. } \\
\text { Varón: Suspiro, pero no lloro, al } \\
\text { menos no hago llorar sabiendo } \\
\text { que soy guapo amores me han de } \\
\text { sobrar. } \\
\text { (Cumananas ejecutadas por los } \\
\text { niños de la I.E. del } 4 \text { to grado de } \\
\text { primaria de la I. E. Federico Hel- } \\
\text { guero Seminario-Piura/Perú) }\end{array}$ & $\begin{array}{l}\text { Mujeres: Venezolana nichkanki siki } \\
\text { sapacha nichkanki, venezolana ni- } \\
\text { chkanki ñunu sapacha nichkanki. } \\
\text { Mejor que venezolana unajminita } \\
\text { pashñacha. } \\
\text { Varones: Venezolano nichkanki, } \\
\text { hatun maqtacha nichkanki, vene- } \\
\text { zolano nichkanki qatun chaychayq } \\
\text { nichkanki. Mejor que venezolano ta- } \\
\text { laverino maqtacha. } \\
\text { Traducción: } \\
\text { Mujeres: Venezolana potona, estás } \\
\text { diciendo, venezolana con grandes te- } \\
\text { tas, estás diciendo. Mejor que la vene- } \\
\text { zolana es la señorita unajmina. } \\
\text { Varones: venezolano estás dicien- } \\
\text { do al joven grande, venezolano estás } \\
\text { diciendo, con grandes cositas estás } \\
\text { diciendo. Mejor que venezolano es el } \\
\text { joven talaverino. } \\
\text { (Creado por el Elenco de Danzas War- } \\
\text { ma Kuyay de la UNAJMA) }\end{array}$ \\
\hline
\end{tabular}


- En las cumananas: La mujer desprecia al varón por condición de pobre, mientras que el varón no se aflige, con un alto grado autoestima y muy orgulloso le hace saber que no es la única. Se hace uso de metáforas e ironías.

- En las coplas del carnaval: Las mujeres unajminas hacen notar que son mejores que las mujeres venezolanas por más atributos físicos que estas tengan. La respuesta de los varones es la misma. Pero en ambos casos no se dice el porqué son mejores. Se hace uso de eufemismos, pero tan bien se usa un lenguaje atrevido.

\begin{tabular}{|c|c|}
\hline La cumanana & Las coplas del carnaval \\
\hline $\begin{array}{l}\text { Mujer: Mis amigas me fasti- } \\
\text { dian con este cholo sin gra- } \\
\text { cia, pero yo no quiero tener } \\
\text { un murciélago en mi casa. } \\
\text { Varón: China malagradecida } \\
\text { mejor me iré con tu hermana, } \\
\text { hoy haré pedido y me casaré } \\
\text { mañana. } \\
\text { (Cumananas ejecutadas por } \\
\text { los niños de la I.E. del 4to } \\
\text { grado de primaria de la I. E. } \\
\text { Federico Helguero Semina- } \\
\text { rio-Piura/Perú) }\end{array}$ & $\begin{array}{l}\text { Varones: } \\
\text { A las de la UNAJMA, a las arguedianitas } \\
\text { yo las quiero, yo las amo } \\
\text { ellas son ñuñusapas, ellas son sikisapas; } \\
\text { pero piden matrimonio } \\
\text { y no quieren chaca chaca. (Bis) } \\
\text { Mujeres: } \\
\text { A los de la UNAJMA, a los arguedianitos } \\
\text { yo los quiero, yo los amo. } \\
\text { ellos son waqrasapas, ellos son trago supis; } \\
\text { pero no quieren casarse, } \\
\text { porque tienen chikitito. (Bis) } \\
\text { (Creado por el Elenco de Danzas Warma } \\
\text { Kuyay de la UNAJMA) }\end{array}$ \\
\hline
\end{tabular}

- En las cumananas: En estos versos, la mujer desprecia al varón por su condición de no ser agraciado físicamente, en el anterior era por ser pobre. Sin embargo, el varón no se amilana y hace saber que se casará con su hermana. Se hace uso de metáforas.

- En las coplas del carnaval: Los varones declaran su amor interesado solo por los atributos físicos de las mujeres, pero se 
decepcionan porque ellas prefieren el matrimonio antes que tener relaciones sexuales. Las mujeres también declaran su amor, pero recurren a los insultos despreciativos, así como eufemismos para referirse al sexo masculino. Se evidencia nuevamente el uso de anáforas.

\section{b) Contrapuntos picaros}

Aluden al doble sentido, se inicia cuando una de las partes provoca al otro con cierta malicia atrevida y mayormente con connotaciones sexuales. Se utilizan figuras literarias como los eufemismos para referirse implícitamente al aspecto sexual, pero también se expresan explícitamente esos términos.

\begin{tabular}{|l|l|}
\hline \multicolumn{1}{|c|}{ La cumanana } & \multicolumn{1}{|c|}{ Las coplas del carnaval } \\
\hline Varón: & Varones: \\
Me puse a lavar a un negro & Me gusta tu fuste, \\
a ver si se desteñía & me gusta tu encaje \\
cuanto más lo jabonaba & pero más te gusta \\
más negro se me ponía. & que yo te encaje. \\
Varón: & Mujeres: \\
Yo también bañé a un blanquito & Te gusta mi fuste, \\
a ver qué cosa decía & te gusta mi encaje \\
le metí un dedo al potito & Pero no te gusta \\
y el maricón se movía. & que otro me encaje. \\
(Contrapunto entre Fernando Ba- \\
rranzuela y Juan Manuel Guar- \\
dado)
\end{tabular}

- En las cumananas: En cuanto al uso del lenguaje, el sentido figurado apela al hipérbaton no solo lineal sino en todo el verso, así como el sentido de este. La hipérbole con el que tramita el remate lo hace atractivo y humorístico.

- En las coplas del carnaval: Se recurre a usar el doble sentido de las palabras, con un coqueteo discreto con la replana. E1 
uso del hipérbaton es lineal, así como en todo el verso, el remate no es hiperbólico sino metafórico.

\section{c) Contrapuntos amorosos}

Tratan del amor se dan de varón a mujer y viceversa, se utilizan metáforas para enamorar o conquistar. El lenguaje es romántico. En el caso de las coplas del carnaval observamos el uso constante de anáforas. Esto permite conservar el ritmo del contrapunto.

\begin{tabular}{|c|c|}
\hline La cumanana & Las coplas del carnaval \\
\hline Varón: & Varones: \\
\hline Paromítare bráncare & Talaverinita, dulce cariñito, \\
\hline paromítare bráncare & coge tu mantita, \\
\hline catay & para ir conmigo. (Bis) \\
\hline si tú me quiérere & Mujeres: \\
\hline si tú me quiérere & Talaverinito, precioso chiquillo, \\
\hline échame ar áncare & limpia tu moquillo \\
\hline velay. & para ir contigo. (Bis) \\
\hline Mujer: & Varor \\
\hline Cardito negro & Talaverinita linda \\
\hline cardito negro & $\begin{array}{l}\text { Talaverinita, linda sunqu suwa, } \\
\text { oiitos marrones }\end{array}$ \\
\hline por qué me espinas & dueña de mi vida (Bis) \\
\hline por qué me espinas & 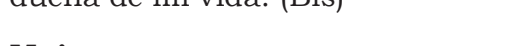 \\
\hline con tu mirar & Mujeres: \\
\hline velay. & Talaverinito, lindo muchachito, \\
\hline $\begin{array}{l}\text { (Cumanana entre hombre } \\
\text { afrodescendiente }\end{array}$ & $\begin{array}{l}\text { jilguero nocturno } \\
\text { amor de mi vida (Bis) }\end{array}$ \\
\hline $\begin{array}{l}\text { blanca de Piura recopilado } \\
\text { por el Padre Justino Ra- } \\
\text { mirez) }\end{array}$ & $\begin{array}{l}\text { (Contrapuntos de la agrupación } \\
\text { cultural Sunqu sua de Talavera) }\end{array}$ \\
\hline
\end{tabular}

- En las cumananas: Son versos antiguos donde un hombre afrodescendiente le pide a su amada blanca que si lo quiere se lo lleve con ella. A lo que ella corresponde con el mismo 
cariño. Hay una riqueza metafórica constante y uso de anáforas.

- En las coplas del carnaval: Las mujeres y los varones se declaran amor mutuo, resaltando sus virtudes y cualidades físicas con un lenguaje dulce, haciendo uso de metáforas.

\begin{tabular}{|l|l|}
\hline \multicolumn{1}{|c|}{ La cumanana } & \multicolumn{1}{|c|}{ Las coplas del carnaval } \\
\hline Varón: & Varones: \\
Buenos dias negrita & Esos limones de tu huertito \\
te vengo hablar de amor & esos limones de tu huertito \\
yo soy tu negrito lindo & están maduros para mí \\
escúchame por favor. & para chuparlos a solas. \\
Mujer: & Mujeres: \\
Como el agua del río & Esos limones de mi huertito \\
yo te quise mucho mejor & esos limones de mi huertito \\
pero me cambiaste por mujer blanca & están maduros para ti \\
que hoy te causa mucho dolor. & no lo pierdas por sonso. \\
(Cumanana del IV concurso descu- \\
briendo cumaneros mercedinos 2011 \\
en Piura) & (Contrapuntos de la agrupa- \\
& ción cultural Sunqu sua de \\
& \\
\hline
\end{tabular}

- En las cumananas: Se habla de un desengaño amoroso, el hombre es zalamero y suplicante, se hace notar la rivalidad entre la mujer blanca y negra. En los versos se utiliza el simil con un lenguaje denotativo.

- En las coplas del carnaval: Aborda el tema amoroso, pero también erótico y satírico, expresan los sentimientos en forma directa y en eso radica parte de su sinceridad y picardía. Se usan metáforas y se apelan a un recurso natural para trasponer los sentidos. El lenguaje es connotativo con una fuerte carga de sensualidad. 


\section{Conclusiones}

- El Perú es un país diverso en donde se aprecia la convivencia de varias culturas, que se relacionan y comparten ciertas características manteniendo sus peculiaridades e identidades colectivas. En la diversidad rescatamos la riqueza cultural de los pueblos, a pesar de las interacciones continuas que se suscitan en el tiempo de forma dinámica, preservando sus expresiones culturales.

- La memoria de las culturas se guarda a través de las historias escritas, de la tradición oral — como los relatos, los cuadros, los nombres de la personas y pueblos, la vestimenta, la comida- pero también a través de música. Por eso es necesario difundirlas y darlas a conocer de generación en generación.

- La cumanana y el pukllay taki (coplas del carnaval) son géneros líricos musicales, pero al mismo tiempo son formas de memoria cultural. Por medio de ellas se visibiliza y se recrea el sentir de las personas y la forma cómo alegran y fortalecen la vida con libertad a pesar de haber pasado por momentos históricos lamentables.

- Las escuelas son los centros de revitalización cultural a través del estímulo del cultivo de estas artes; pero también se debe promover otros espacios de difusión, o recuperar aquellos espacios en donde se practicaba anteriormente; esto para el caso de las cumananas.

- El contrapunto en la cumanana y el pukllay taki tienen diferencias, en cuanto al lugar, mientras las cumananas se practican en lugares cerrados; los pukllay taki, en espacios abiertos con participación masiva de comparsas. Respecto al tiempo, las cumanas se practican en cualquier momento del año y los pukllay taki solo en los carnavales. En la composición literaria se nota que la rima es más armoniosa en las cumananas.

- El contrapunto en la cumanana y el pukllay taki no obstante tienen matices culturales diferentes se encuentran similitu- 
des ya que ambas comparten la misma temática amorosa, despreciativa y pícara; mientras que, en su composición literaria, encontramos que se utilizan figuras retóricas con rima asonante, consonante y mixta. Sin embargo, la métrica no es precisa para ambos casos.

\section{Referencias bibliográficas}

Alarcón, Alberto (1992). El canto de la Achupalla. La cumanana en Piura. Lima: Lluvia Editores.

Arguedas, José (1985). Indios, mestizos y señores. Lima: Edit. Horizonte

-. (1938/1989). Canto Kechwa (con un ensayo sobre la capacidad de creación artística del pueblo indio y mestizo) Lima: Edt. Horizonte.

Bellido, Alfredo y otros (2005). Visión Andina del Carnaval. Andahuaylas. Centro de Estudios Andinos Vida Dulce: Gráfica San Martín.

Calvo Pérez, Julio. (2014). Diccionario etimológico de palabras del Perú. Lima: Universidad Ricardo Palma.

Carazas, Milagros (2011). Estudios Afroamericanos: ensayos sobre identidad y literatura afroperuanas. Lima: Centro de desarrollo étnico.

- (2017). Cumanana y memoria oral en la Historia de Yapatera de Fernando Barranzuela. D Palenque Literatura y Afrodescendencia. Lima. Año II. N. ${ }^{\circ} 2$.

Gutiérrez, Arturo (2003). Música y músicos de Andahuaylas. Recuperado de: http://redchanka.blogspot.com/2013/04/musica-y-musicos-de-andahuaylas.html

Huamán, Carlos (2004). Pachachaka. Puente sobre el mundo narrativa, memoria y simbolo en la obra de José María Arguedas. México D.F.: El Colegio de México.

Lira, Jorge A y Mejía Huamán, Mario (2008). Diccionario quechua-castellano. Lima: Fondo Editorial de la Universidad Ricardo Palma. 
Navarro, Víctor (1943). Pukllay Taki. Sobretiro de la Revista del Instituto Americano de Arte. Año 1, N. 1 Vol 1.

Rocca, Luis (2010) Herencia de Esclavos en el norte del Perú (Cantares, danzas y música). Lima: Centro de Desarrollo Étnico-CEDET.

Tompkins, William D. (2011) Las tradiciones musicales de los negros de la costa del Perú. Lima. Centro de Música y Danza de la Pontifica Universidad Católica del Perú/ Centro Universitario de folklore de la Universidad Nacional Mayor de San Marcos. 